\title{
Density Functional Theory Calculations for Diaminonaphthalene Molecules group
}

\author{
Ali Taher Mohi
}

\author{
Physics department-College of Education- University of Mustansiriyah \\ E-mail: dr.alimohi@yahoo.com
}

\section{$\underline{\text { Abstract }}$}

Theoretical studies for calculating molecular structure parameters of naphthalene and its simplest derivatives with electron-donating groups (di-amino) in different positions were performed using density functional theory (DFT). Based on B3LYP with 6-31 (d,p) basis set was used to investigate the effect on the electronic and structure properties for the positional variation of the amino substituents in the naphthalene. The optimized structures, total energies, electronic states, energy gaps, ionization potentials, electron affinities, chemical potential, global hardness, softness, global electrophilictity, dipole moment and dipole polarizability were calculated. The harmonic vibrational frequencies calculated and compared with available experimental data. The results showed a decrease in energy gaps and the presence of the electron-donating groups leads to easy oxidation.

Keywords: DFT, Ionization potential, electron affinity, energy gap, and IR spectrum.

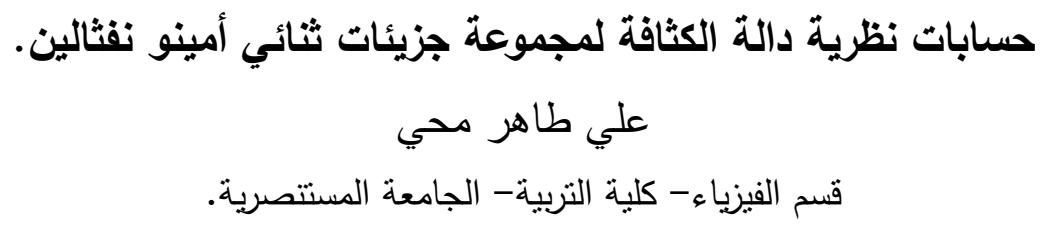

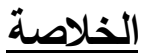

دراسة نظرية لحساب معاملات خصائص التركيب الجزيئي للنفثالين ومشتقاتها البسيطة مع مجموعة المانحة للإلكترون (ثنائي الأمين) في مختلف

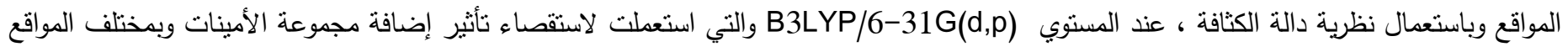

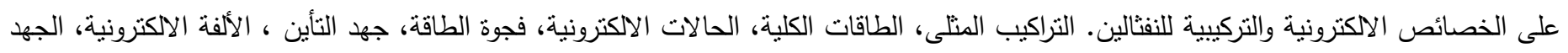

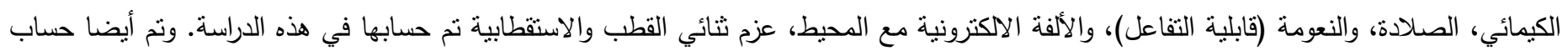

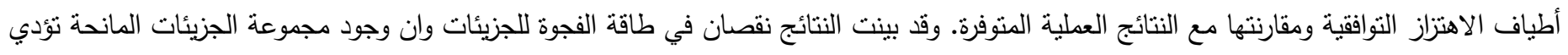
إلى سهولة أكسدة الجزيئات المدروسة.

\section{Introduction}

Aromatic compounds are a large class of conjugated $\pi$-electron systems of great importance in many research areas, such as materials science, astrochemistry [1] and molecular electronics [2-4]. In the last case molecules with electron-accepting (high electron affinity) and electron-donating (low ionization potential) properties strongly effecting chargetransporting properties of thin films based on these materials are often used. In contrast to inorganic materials that consist of covalent or ionic bonds of atoms over the entire solids, organic materials are based on independent molecules and are characterized by weak intermolecular interactions. As a result, characteristics of energy levels and energy transformation for single molecules and condensed media differ a little, while the difference among these characteristics for inorganic compounds is much stronger. Thus, the properties of individual molecules can be used to describe molecular solids in the first approximation. Molecular electronics is one of the most 
important developments in modern-day technology [5]. Naphthylamine is the starting material in the dye manufacturing and rubber industry. Naphthylamine can be oxidized by chromic acid into naphthoquinone which is the fundamental ring structure related with vitamin $\mathrm{K}$. Diaminonaphthalene used for determination of selenium. Also used for the detection of nitric oxide via a sensitive fluorometric assay of nitrite (NO2-), diaminonaphthalene used also in the production of polymers and in organic semiconductor [6]. Organic semiconductors have been profitably used since the time of their discovery [7] due to their flexibility, low cost [8], and intrinsic properties such as light emission. Some applications of organic semiconductors include: organic light emitting diodes (OLEDs), photovoltaic cells, thin film transistors, and biosensors. It is important to mention that most of the materials used for these applications contain conjugated p systems [9]. The theoretical study of the electronic structure has proven to be very conducive to predict physicochemical properties of a large number of donoracceptor systems. Moreover, theoretical calculations such as geometry optimizations are very important for understanding the pathways of electron and/or energy transfer processes in photoactive assemblies [10]. The substituents attached to the molecular framework can enhance or diminish the reactivity. The mechanistic conclusions based on the linear relationships with free energy have been extremely fruitful. Accordingly, changes in reactivity in one reaction series caused by changes in substitution are related to changes in equilibrium or reactivity in another series caused by the same changes in substitution [11]. The goal of this work is the theoretical investigation of the effect of substitution groups (di-amino) on electronic and structural properties and the reactivity of naphthalene molecular and the evaluation of their dipole polarizability by density functional theory (DFT) method and comparison with experimental results.

\section{Computational details}

Figure 1 represents the molecules under study. All the computational studies were carried out using the density functional theory (DFT) methods implemented in the Gaussian 09 suite of programs [12]. The molecular properties of the compounds have been computed by DFT using the standard 6-31G(d,p) basis set. In the DFT calculations the Lee, Yang and Parr correlation functional (BLP) [13] is used together with Becke's three parameters [14] exchange functional
B3LYP. Conformational analysis of the molecules has been performed to have an idea about the lowest energy structures of the species. The geometry optimization was performed at the B3LYP density functional theory with the same basis set $[12,15]$. Harmonic vibrational frequencies were computed at the same level of theory. The hybrid functional B3LYP has shown to be highly successful for calculation the electronic properties such as ionization potentials, electronic states and energy gaps [16-18].The DFT partitions the electronic energy as $E=E_{T}+E_{V}+E_{J}+E_{X C}$, where $E_{T}, E_{V}$, and $E_{J}$ are the electronic kinetic energy, the electron nuclear attraction and the electron-electron repulsion terms respectively. The electron correlation is taken into account in DFT via the exchange correlation term $\mathrm{E}_{\mathrm{XC}}$, which includes the exchange energy arising from the antisymmetry of the quantum mechanical wavefunction and the dynamic correlation in the motion of individual electrons; it makes DFT dominant over the conventional Hartree-Fock (HF) procedure [19].The geometry optimized structures are obtained by restricted closed-shell formalism and without any symmetry restriction, and vibrational analysis for each structure does not yield any imaginary frequencies, which indicates that the structure of each molecule corresponds to at least a local minimum on the potential energy surface [20].In this investigation, the more relevant electronic potential (IP), electron affinities (EA), chemical potential (K) it is the negative of electronegativity $(\chi)$, hardness $(\eta)$, softness (S), electrophilic index $(\omega)$ and the electric dipole polarizability $(\alpha)$ were calculated. The ionization potential is calculated as the energy difference between the energy of the molecule derived from electrontransfer (radical cation) and the respective neutral molecule; IPv = Ecation - En. The EA was computed as the energy difference between the neutral molecule and the anion molecule: EA = En- Eanion [21]. The highest occupied molecular orbital (HOMO) and the lowest unoccupied molecular orbital (LUMO) energy were also used to estimate the IP and EA in the framework of Koopmans' theorem: IP $=-\varepsilon_{\text {HOMO }}$ and $\mathrm{EA}=-\varepsilon_{\text {LUMO }}$ [22].Within the framework of the density functional theory (DFT), one of the global quantities is chemical potential $(\mathrm{K})$, which is measures the escaping tendency of an electronic cloud, and equals the slope of the Energy versus $\mathrm{N}$ (number of electrons) curve at external potential $v(r)[23]$ : 
$K=\left[\frac{\partial E}{\partial N}\right]_{v(r)}$

Finite difference approximation to Chemical Potential gives[23],

$$
K \approx-\chi=-(I P+E A) / 2
$$

The theoretical definition of chemical hardness has been provided by the density functional theory as the second derivative of electronic energy with respect to the number of electrons $\mathrm{N}$, for a constant external potential $v(r)[23]$ :

$$
\eta=\frac{1}{2}\left[\frac{\partial^{2} \mathrm{E}}{\partial \mathrm{N}^{2}}\right]_{v(\mathrm{r})}=\frac{1}{2}\left[\frac{\partial \mu}{\partial \mathrm{N}}\right]_{v(\mathrm{r})}
$$

Finite difference approximation to Chemical hardness gives,

$$
\eta=(I P-E A) / 2
$$

For insulators and semiconductor, hardness is half of the energy gap $\left(\varepsilon_{\text {HоMO }}-\varepsilon_{\text {LUMO }}\right)$, and the softness is given by [22] :

$$
\mathrm{S}=\frac{1}{2 \eta}=\left(\frac{\partial^{2} \mathrm{~N}}{\partial \mathrm{E}^{2}}\right)_{v(\mathrm{r})}=\left(\frac{\partial \mathrm{N}}{\partial \mu}\right)_{v(\mathrm{r})}
$$

Electrophilicity index is a measure of energy lowering due to maximal electron flow between donor and acceptor. Electrophilicity index $(\omega)$ is defined as [19],

$$
\omega=\frac{\mu^{2}}{2 \eta}
$$

One of the other global properties is the electric dipole polarizability, which is a measure of the linear response of the electron density in the presence of an infinitesimal electric field, F, and represents a secondorder variation in the energy, viz.[23] :

$$
\alpha=-\left(\frac{\partial^{2} \mathrm{E}}{\partial \mathrm{F}_{\mathrm{a}} \partial \mathrm{F}_{\mathrm{b}}}\right) \quad \mathrm{a}, \mathrm{b}=\mathrm{x}, \mathrm{y}, \mathrm{z}
$$

If some of applied molecules are planar and some are not, it will be useful to report polarizability quantities that are invariant to the choice of coordinate system. One of them is the mean polarizability $\langle\alpha\rangle$ is evaluated using the equation [19].

$$
<\alpha>=\frac{1}{3}\left(\alpha_{\mathrm{xx}}+\alpha_{\mathrm{yy}}+\alpha_{\mathrm{zz}}\right)
$$

where $\alpha x x, \alpha y y$ and $\alpha z z$ are the eigenvalues of the polarizability tensor.

\section{Results and discussion}

\subsection{Molecular geometry}

The optimized structure parameters of molecules calculated by DFT-B3LYP levels with the 6-31G(d,p) basis set are listed in the Table (1) in accordance with the atom numbering scheme given in figure1. Table (1) compares the calculated bond lengths and angles for (1
- 6) molecules with those experimentally available from X-ray diffraction data [24].From the theoretical values, we can find that most of the optimized bond angles are slightly larger than the experimental values, due to the theoretical calculations belong to isolated molecules in gaseous phase and the experimental results belong to molecules in solid state.

\subsection{Energies}

Table (2) shows the values of the total energy and electronic states for the analyzed structures and the energy gap $\left(\varepsilon_{\mathrm{LUMO}}-\varepsilon_{\text {HOMO }}\right)$ of the studied molecules. It is clear that from Table (2), the total energy for all diaminonaphthalene molecules is approximately the same in which this refer that the total energy is independent on the position of the diamino radical in the ring, and it is observed that substitution of diamino groups causes increasing the HOMO and LUMO energy, it is known that the electron donating substituents increasing the LUMO and HOMO energies [25], and energy gap decreased. Therefore, the presence of substituent decreases the energy gaps improves the conductivities and also enhances the solubilities of these molecules. The LUMO-HOMO energy gaps of diaminonaphthalene molecules is small than that of the original molecules, with decreasing energy gap, electrons can be easily excited from the ground state $[26,27]$. This effect of the side group was the largest in molecule 5 it has energy gap of $(3.991 \mathrm{eV})$. The energy gap of naphthalene $(4.821 \mathrm{eV})$ agrees with experimental value $(4.45 \mathrm{eV})$. Table 2 shows also the symmetry of studied molecules, the molecule 1 is planar with inversion center and have D2h symmetry (high symmetry), and have higher electronegativity, while molecule 5 is planer and have Cs symmetry (low symmetry), and have lower electronegativity.

\subsection{Molecular Orbital Shape}

The 3D plot of the HOMO and LUMO orbital of diaminonaphthalene from B3LYP/6-31(d,p) DFT calculations are shown in figures ((2) -(7)). It can be seen from this figures, that the majority of the molecular orbital density in HOMO and LUMO orbitals is delocalized along the C-C backbone, i.e. the electronic clouds of these orbitals are localized on the naphthalene ring. This was caused by the nucleophilic attack on aromatic ring. In the electron-donating groups (NH2), the electrons are donated to the $\pi$-system by the amino groups. Therefore, the aromatic rings in diaminonaphthalene groups are negatively charged, adding the substituent groups to the ring changes the 
HOMO and LUMO levels. In all molecules the HOMO shows a bonding character and LUMO shows an antibonding character.

\subsection{Some important variables}

B3LYP functional used in this study has a high efficient to calculate the electronic properties for the organic studied molecules, such as ionization potentials (IP), electron affinities (EA), chemical potential (K), absolute hardness ( $)$, absolute softness (S), electrophilic index $(\omega)$. The properties that are displayed in figures $8,9,10,11,12$ and figure 13 , respectively, for each variable are computed by two different ways: The first one being energy-vertical is based on the differences of total electronic energies when an electron is added or removed in accordance with the neutral molecule. The second one is based on the differences between the HOMO and LUMO energies of the neutral molecule and is known as Koopmans' theorem (KT).The calculated properties for each variable as shown in figures (8-13) clearly reveal that these diaminonaphthalene compounds have a tendency to donate electrons instead of capturing them. The ionization potential for the diaminonaphthalene molecules group is higher than that for the original molecule, but the 5 molecule has the lowest value of ionization potential, this indicates that the diaminonaphthalene molecule needs small energy to become cation comparing with the others. The strength of a donor molecule is measured by its electron affinity (EA) which is the energy released when adding one electron to LUMO. A donor must have a low EA, adding the radical to the ring leads to reduce the ability of the electron affinity for the molecule; EA for molecule 5 is the lowest, as we see in figure (9). The calculation value of IP, EA and energy gaps for molecules 1 is in a good agreement with experimental value $8.11 \pm 0.001 \mathrm{eV},-0.2 \pm 0.05 \mathrm{eV}$, and $4.5 \pm 0.05$ $\mathrm{eV}$ [28], respectively.Few interesting observations have been made from the results that are shown in figures (813) obtained through the energy-vertical and KT methods. The electron affinities (EA) computed from the energy of the lowest unoccupied molecular orbital (LUMO) are higher for all studied molecules than that of the energy-vertical method and in positive. The ionization potential (IP) that results from the highest occupied molecular orbital is smaller for all study molecules than that of the energy-vertical method. Figure 4 shows that the values of chemical potential are calculated by two ways are identified. From the previous investigations, it has been found that for almost all the commonly used exchange-correlation functional such as B3LYP, B3PW91, Koopman's theorem is not satisfied accurately [21]. The behavior of electronegativity, softness and electrophilic index for the studied molecules shows the magnitude large than these for the original ring, adding the radicals give the molecule more softness. The molecules dipole moment represents a generalized measure of bond properties and charge densities in a molecule [21]. Molecule with electron accepter group due to better charge distribution and increasing distance have higher dipole moment[23], from Table (3) molecule 4 has higher dipole moment (2.904 Debye) .The results of the calculated polarizability for $(1-6)$ molecules in table (3) showed that all substitution groups leads to increase the average polarizability and cause more reactive then the original molecules (1). The molecules 2 and 3 have average dipole polarizability equal to 122.463 and 124.260 a.u, respectively; they have the highest polarizability and have highest reactivity. This due to the ring delocalizing $\pi$ electron resonance from the phenyl groups [23].

\subsection{IR Spectra}

The IR spectra of (1- 6) molecules are provided in figure (14). The harmonic vibrational frequencies calculated to study molecules at B3LYP level using the $6-3 \mathrm{G}(\mathrm{d}, \mathrm{p})$ basis set. The number of vibrational frequency modes depending on the number of atoms $(\mathrm{N})$ in molecules $(3 \mathrm{~N}-6)$, the neutral naphthalene and diaminonaphthalene is characterized by 48 , and 52 normal vibrational modes, respectively. This can be analysis as:

(i) $\mathrm{C}-\mathrm{H}$ vibrations

The $(\mathrm{C}-\mathrm{H})$ stretching vibrations of aromatic molecules in the region $(3200-2900) \mathrm{cm}-1$ which is characteristic region for ready identification of $(\mathrm{C}-\mathrm{H})$ stretching vibrations and particularly the region (3200 $3100) \mathrm{cm}-1$ for asymmetric stretching and (3100 2900) $\mathrm{cm}-1$ for symmetric stretching modes of vibration [21].The present work gives the frequency values at $3173,3180,3192$ and $3206 \mathrm{~cm}-1$ for naphthalene which are consistent with experimental results of 3031, 3058, 3060 and $3065 \mathrm{~cm}-1$ [30]. For diaminonaphthalene (2 6) molecules the $(\mathrm{C}-\mathrm{H})$ stretching stay in the region (3220-3100) cm-1, with slightly increased camper with natural naphthalene.The aromatic molecules frequency has both in-plane $(1700-1100) \mathrm{cm}-1$ and out-of-plane (below $1000 \mathrm{~cm}-1)(\mathrm{C}-\mathrm{H})$ bending vibrations, the inplane vibration for naphthalene calculated at $1459 \mathrm{~cm}-1$ and $1241 \mathrm{~cm}-1$ which a good agreement with experimental results 1460 and $1239 \mathrm{~cm}-1$, and the outof-plane $(\mathrm{C}-\mathrm{H})$ deformation vibrations calculated at 
1043 and $804 \mathrm{~cm}-1$ are agreement with experimentally predicted in 1209 and $970 \mathrm{~cm}-1[29]$. For diaminonaphthalene the in-plane vibration calculated at (1512 - 1195) $\mathrm{cm}-1$ and for out-of-plane $(\mathrm{C}-\mathrm{H})$ bending vibrations are found in the region $(1002-810)$ cm-1.

(ii) Phenyl ring vibrations: (C - C) stretching vibrations

The aromatic $(\mathrm{C}-\mathrm{C})$ stretching vibrations occurs in the region (1686 - 1554) cm-1 for naphthalene while the experimental value at $(1653$ - 1504) $\mathrm{cm}-1$, for diaminonaphthalene $(\mathrm{C}-\mathrm{C})$ stretching located at $(1700$ - 1450)cm-1. As for the previous band, $(\mathrm{C}-\mathrm{C})$ stretching and in-plane $(\mathrm{C}-\mathrm{H})$ bending vibrations have been identified.

(iii) $\mathrm{NH} 2$ vibrations

The amino group has been many fundamentals modes, which are stretching and bending bond, torsion and inversion. In all the aromatic amino, the $(\mathrm{N}-\mathrm{H})$ stretching frequencies occurs in the region (3300 $3700) \mathrm{cm}-1$, the asymmetric stretching mode appears to be calculated at the high wave number $3672 \mathrm{~cm}-1$ and the symmetric stretching mode appear at (3550 - 3660) $\mathrm{cm}-1$ [30].In addition $\mathrm{NH} 2$ group has scissoring , rocking, waggins and torsion mode, the scissoring mode of the NH2 group appears in the region (1625 1420) $\mathrm{cm}-1$, the $\mathrm{NH} 2$ rocking and tensional appears at $1041 \mathrm{~cm}-1$ and $102 \mathrm{~cm}-1$

\section{Conclusions}

DFT in this study are used to compute geometry optimization and electronic properties of naphthalene and diaminonaphthalene by using B3LYP function. The calculated electronic properties such as ionization potential, electron affinity, electronegativity, hardness, softness and electrophilic index by using two different ways: energy-vertical method and KT method, the important conclusions are:Geometry optimization for molecule 1 has been found in a good agreement with experimental data, while for other studied molecules (2 -6) it has not been found a reference data.The total energies for diaminonaphthalene found not dependent on the position of the nitro radical in the ring and substitution amino group causes decreasing energy and more stability.The presence of the substituents decreases the energy gap of the molecules; this is one of the important properties obtained in this work. Small energy gap means small excitation energies of manifold of the exited states. The electronic properties (IP, EA, $\mathrm{K}, \eta, S, \omega)$ was calculated by using Energy-vertical method are a good agreement with experimental result and better than that was calculated by using KT method, thus Koopman's theorem is not satisfied accurately.The results showed that all substitution groups leads to increase the average polarizability and dipole moment and cause to more reactive than original molecules.In IR spectra calculation shows a good agreement with experimental data for naphthalene (molecules 1), adding the amino groups leads to increasing the vibrational mode, and highest stretching vibrational wave numbers and it's gave suitable positions for $\mathrm{NH} 2$ with carbon atoms in phenyl ring.

Molecule 5 is the best option for p-type organic semiconductors because of its better HOMO - LUMO ratio and other electronic properties.

Table (1): Optimized geometrical parameters of molecules, bond length $\mathrm{R}(\boldsymbol{\AA})$, bond angles $\left({ }^{\circ}\right)$.

\begin{tabular}{|c|c|c|c|c|c|c|}
\hline Molecules & bond length & Our data & Expt. & bond angles & Our data & Expt. \\
\hline \multirow{5}{*}{1} & $\mathrm{R}\left(\mathrm{C}_{3}-\mathrm{C}_{4}\right)$ & 1.426 & 1.412 & $\mathrm{~A}\left(\mathrm{C}_{10}-\mathrm{C}_{3}-\mathrm{C}_{4}\right)$ & 120.441 & 119.5 \\
\hline & $\mathrm{R}\left(\mathrm{C}_{3}-\mathrm{C}_{10}\right)$ & 1.430 & 1.422 & $\mathrm{~A}\left(\mathrm{C}_{15}-\mathrm{C}_{10}-\mathrm{C}_{3}\right)$ & 121.804 & 120.2 \\
\hline & $\mathrm{R}\left(\mathrm{C}_{14}-\mathrm{C}_{15}\right)$ & 1.445 & 1.417 & $\mathrm{~A}\left(\mathrm{C}_{10}-\mathrm{C}_{15}-\mathrm{C}_{14}\right)$ & 119.098 & 120.5 \\
\hline & $\mathrm{R}\left(\mathrm{C}_{11}-\mathrm{H}_{16}\right)$ & 1.400 & 1.092 & $\mathrm{~A}\left(\mathrm{H}_{7}-\mathrm{C}_{10}-\mathrm{C}_{3}\right)$ & 120.155 & 117.0 \\
\hline & $\mathrm{R}\left(\mathrm{C}_{15}-\mathrm{H}_{18}\right)$ & 1.087 & 1.092 & $\mathrm{~A}\left(\mathrm{H}_{18}-\mathrm{C}_{15}-\mathrm{C}_{10}\right)$ & 118.469 & 119.9 \\
\hline \multirow{5}{*}{2} & $\mathrm{R}\left(\mathrm{C}_{1}-\mathrm{C}_{2}\right)$ & 1.378 & & $\mathrm{~A}\left(\mathrm{C}_{2}-\mathrm{C}_{1}-\mathrm{C}_{6}\right)$ & 119.606 & \\
\hline & $\mathrm{R}\left(\mathrm{C}_{1}-\mathrm{C}_{6}\right)$ & 1.437 & & $\mathrm{~A}\left(\mathrm{C}_{1}-\mathrm{C}_{6}-\mathrm{N}_{20}\right)$ & 116.860 & \\
\hline & $\mathrm{R}\left(\mathrm{C}_{1}-\mathrm{N}_{17}\right)$ & 1.420 & & $\mathrm{~A}\left(\mathrm{C}_{1}-\mathrm{C}_{2}-\mathrm{H}_{8}\right)$ & 119.476 & \\
\hline & $\mathrm{R}\left(\mathrm{C}_{2}-\mathrm{H}_{8}\right)$ & 1.088 & & $\mathrm{~A}\left(\mathrm{C}_{1}-\mathrm{N}_{17}-\mathrm{H}_{16}\right)$ & 113.145 & \\
\hline & $\mathrm{R}\left(\mathrm{N}_{17}-\mathrm{H}_{18}\right)$ & 1.013 & & $\mathrm{~A}\left(\mathrm{H}_{21}-\mathrm{N}_{20}-\mathrm{H}_{22}\right)$ & 110.370 & \\
\hline \multirow{5}{*}{3} & $\mathrm{R}\left(\mathrm{C}_{1}-\mathrm{C}_{2}\right)$ & 1.384 & & $\mathrm{~A}\left(\mathrm{C}_{2}-\mathrm{C}_{1}-\mathrm{C}_{6}\right)$ & 118.689 & \\
\hline & $\mathrm{R}\left(\mathrm{C}_{9}-\mathrm{C}_{14}\right)$ & 1.374 & & $\mathrm{~A}\left(\mathrm{C}_{6}-\mathrm{C}_{1}-\mathrm{N}_{17}\right)$ & 119.25 & \\
\hline & $\mathrm{R}\left(\mathrm{C}_{1}-\mathrm{N}_{17}\right)$ & 1.402 & & $\mathrm{~A}\left(\mathrm{C}_{1}-\mathrm{C}_{2}-\mathrm{H}_{8}\right)$ & 119.877 & \\
\hline & $\mathrm{R}\left(\mathrm{C}_{2}-\mathrm{H}_{8}\right)$ & 1.088 & & $\mathrm{~A}\left(\mathrm{C}_{13}-\mathrm{N}_{20}-\mathrm{H}_{22}\right)$ & 114.269 & \\
\hline & $\mathrm{R}\left(\mathrm{N}_{17}-\mathrm{H}_{18}\right)$ & 1.012 & & $\mathrm{~A}\left(\mathrm{H}_{21}-\mathrm{N}_{20}-\mathrm{H}_{22}\right)$ & 110.885 & \\
\hline \multirow{5}{*}{4} & $\mathrm{R}\left(\mathrm{C}_{1}-\mathrm{C}_{2}\right)$ & 1.382 & & $\mathrm{~A}\left(\mathrm{C}_{2}-\mathrm{C}_{1}-\mathrm{C}_{6}\right)$ & 121.722 & \\
\hline & $\mathrm{R}\left(\mathrm{C}_{9}-\mathrm{C}_{13}\right)$ & 1.379 & & $\mathrm{~A}\left(\mathrm{C}_{1}-\mathrm{C}_{2}-\mathrm{N}_{17}\right)$ & 120.614 & \\
\hline & $\mathrm{R}\left(\mathrm{C}_{6}-\mathrm{N}_{20}\right)$ & 1.397 & & $\mathrm{~A}\left(\mathrm{C}_{2}-\mathrm{C}_{1}-\mathrm{H}_{8}\right)$ & 119.390 & \\
\hline & $\mathrm{R}\left(\mathrm{C}_{1}-\mathrm{H}_{8}\right)$ & 1.088 & & $\mathrm{~A}\left(\mathrm{C}_{6}-\mathrm{N}_{20}-\mathrm{H}_{22}\right)$ & 115.030 & \\
\hline & $\mathrm{R}\left(\mathrm{N}_{17}-\mathrm{H}_{18}\right)$ & 1.011 & & $\mathrm{~A}\left(\mathrm{H}_{21}-\mathrm{N}_{20}-\mathrm{H}_{22}\right)$ & 111.609 & \\
\hline \multirow{5}{*}{5} & $\mathrm{R}\left(\mathrm{C}_{1}-\mathrm{C}_{2}\right)$ & 1.381 & & $\mathrm{~A}\left(\mathrm{C}_{2}-\mathrm{C}_{1}-\mathrm{C}_{6}\right)$ & 121.604 & \\
\hline & $\mathrm{R}\left(\mathrm{C}_{1}-\mathrm{C}_{6}\right)$ & 1.411 & & $\mathrm{~A}\left(\mathrm{C}_{6}-\mathrm{C}_{5}-\mathrm{N}_{20}\right)$ & 121.679 & \\
\hline & $\mathrm{R}\left(\mathrm{C}_{2}-\mathrm{N}_{17}\right)$ & 1.410 & & $\mathbf{A}\left(\mathrm{C}_{9}-\mathrm{C}_{13}-\mathrm{H}_{16}\right)$ & 119.999 & \\
\hline & $\mathrm{R}\left(\mathrm{C}_{13}-\mathrm{H}_{16}\right)$ & 1.086 & & $\mathrm{~A}\left(\mathrm{C}_{2}-\mathrm{N}_{17}-\mathrm{H}_{19}\right)$ & 117.223 & \\
\hline & $\mathrm{R}\left(\mathrm{N}_{17}-\mathrm{H}_{19}\right)$ & 1.013 & & $\mathrm{~A}\left(\mathrm{H}_{21}-\mathrm{N}_{20}-\mathrm{H}_{22}\right)$ & 109.247 & \\
\hline \multirow{5}{*}{6} & $\mathrm{R}\left(\mathrm{C}_{1}-\mathrm{C}_{2}\right)$ & 1.386 & & $\mathrm{~A}\left(\mathrm{C}_{2}-\mathrm{C}_{1}-\mathrm{C}_{6}\right)$ & 120.887 & \\
\hline & $\mathrm{R}\left(\mathrm{C}_{1}-\mathrm{C}_{6}\right)$ & 1.408 & & $\mathrm{~A}\left(\mathrm{C}_{13}-\mathrm{C}_{10}-\mathrm{N}_{20}\right)$ & 120.802 & \\
\hline & $\mathrm{R}\left(\mathrm{C}_{10}-\mathrm{N}_{20}\right)$ & 1.400 & & $\mathrm{~A}\left(\mathrm{C}_{9}-\mathrm{C}_{14}-\mathrm{H}_{18}\right)$ & 120.028 & \\
\hline & $\mathrm{R}\left(\mathrm{C}_{1}-\mathrm{H}_{8}\right)$ & 1.087 & & $\mathrm{~A}\left(\mathrm{C}_{2}-\mathrm{N}_{17}-\mathrm{H}_{19}\right)$ & 113.506 & \\
\hline & $\mathrm{R}\left(\mathrm{N}_{17}-\mathrm{H}_{19}\right)$ & 1.012 & & $\mathrm{~A}\left(\mathrm{H}_{21}-\mathrm{N}_{20}-\mathrm{H}_{22}\right)$ & 110.704 & \\
\hline
\end{tabular}

Table (2): Total energy, electronic states and energy gap for molecules.

\begin{tabular}{|c|c|c|c|c|c|c|}
\hline Structure & Energy(a.u) & Symmetry & \multicolumn{2}{|c|}{$\begin{array}{c}\text { Electronic } \\
\text { States(eV) }\end{array}$} & $\begin{array}{c}\text { Energy } \\
\text { Gaps (eV) } \\
\text { Our data }\end{array}$ & $\begin{array}{c}\text { Energy } \\
\text { Gaps (eV) } \\
\text { Expt. }\end{array}$ \\
\cline { 4 - 5 } & & & HOMO & LUMO & \\
\hline $\mathbf{1}$ & -385.905 & $\mathrm{D}_{2 \mathrm{~h}}$ & -5.800 & -0.979 & 4.821 & $4.45[28]$ \\
\hline $\mathbf{2}$ & -496.624 & $\mathrm{C}_{2}$ & -5.200 & -0.520 & 4.680 & - \\
\hline $\mathbf{3}$ & -496.620 & $\mathrm{C}_{\mathrm{i}}$ & -4.646 & -0.600 & 4.046 & - \\
\hline $\mathbf{4}$ & -496.621 & $\mathrm{C}_{1}$ & -4.784 & -0.513 & 4.271 & - \\
\hline $\mathbf{5}$ & -496.616 & $\mathrm{C}_{\mathbf{5}}$ & -4.604 & -0.613 & 3.991 & - \\
\hline $\mathbf{6}$ & -496.619 & $\mathrm{C}_{2}$ & -4.786 & -0.484 & 4.302 & - \\
\hline
\end{tabular}


Table (3): calculated dipole moment $\mu$ (debye), components of $\alpha_{\mathrm{i}}(\mathrm{i}=\mathrm{xx}, \mathrm{yy}, \mathrm{zz})$ anaverage of the polarizability $\langle\alpha\rangle$ in atomic units for molecules.

\begin{tabular}{|c|c|c|c|c|c|}
\hline molecules & $\mu$ & $\alpha_{x x}$ & $\alpha_{y y}$ & $\alpha_{z z}$ & $\langle\alpha\rangle$ \\
& & & & & \\
\hline 1 & 0.000 & 154.374 & 111.105 & 33.242 & 99.574 \\
2 & 2.247 & 199.617 & 126.434 & 41.345 & 122.463 \\
3 & 0.0035 & 207.654 & 124.664 & 40.460 & 124.260 \\
4 & 2.904 & 184.873 & 137.501 & 40.512 & 120.963 \\
5 & 2.423 & 165.502 & 150.016 & 41.532 & 119.017 \\
6 & 2.248 & 148.538 & 167.261 & 41.126 & 118.975 \\
\hline
\end{tabular}
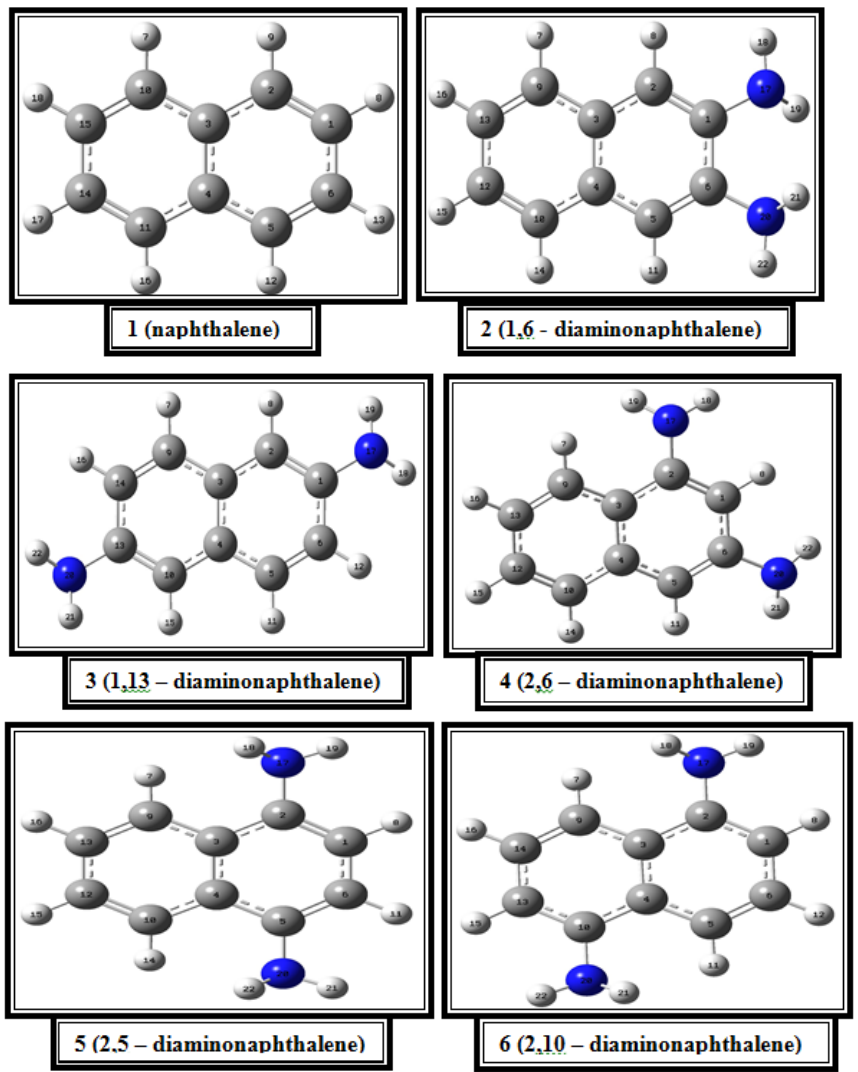

Figure (1): Structures of naphthalene and its derivatives discussed in this work.
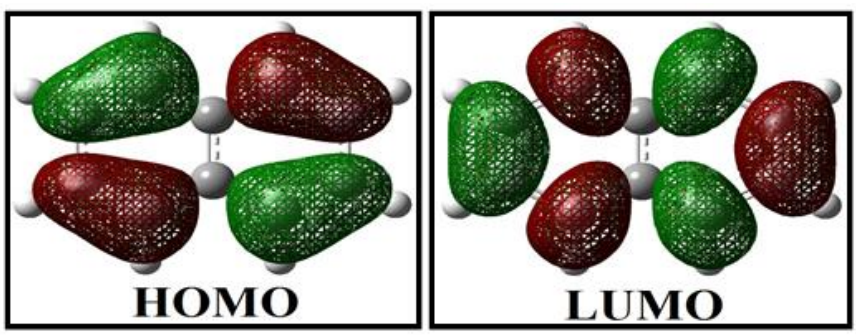

Figure (2): DFT cal., HOMO and LUMO level of molecule 1
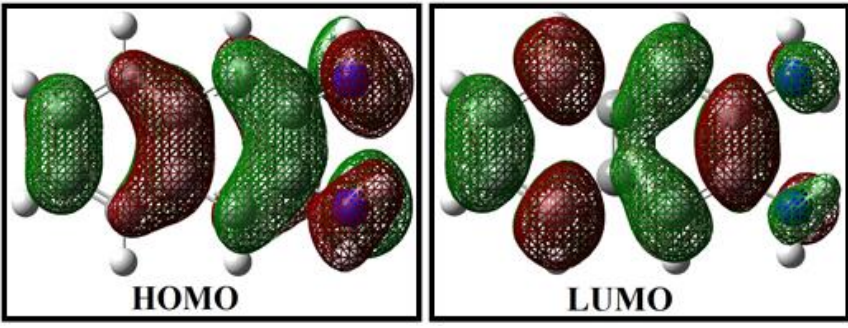

Figure (3): DFT Cal., HOMO and LUMO level of molecule 2
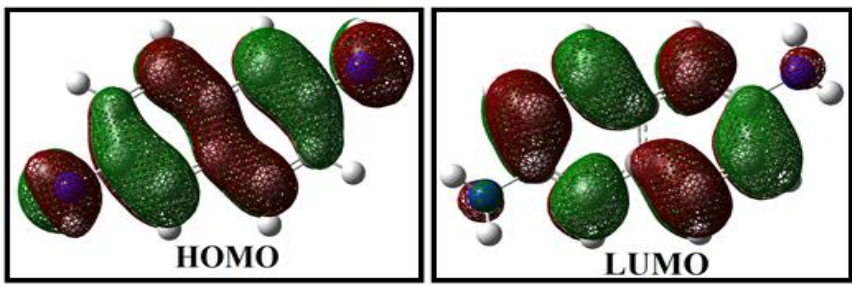

Figure (4): DFT Cal., HOMO and LUMO level of molecule 3
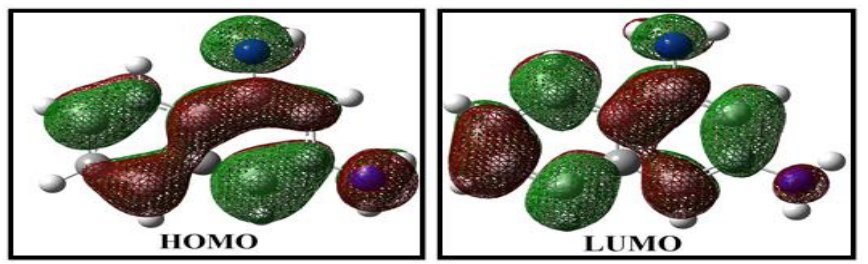

Figure (5): DFT Cal., HOMO and LUMO level of molecule 4
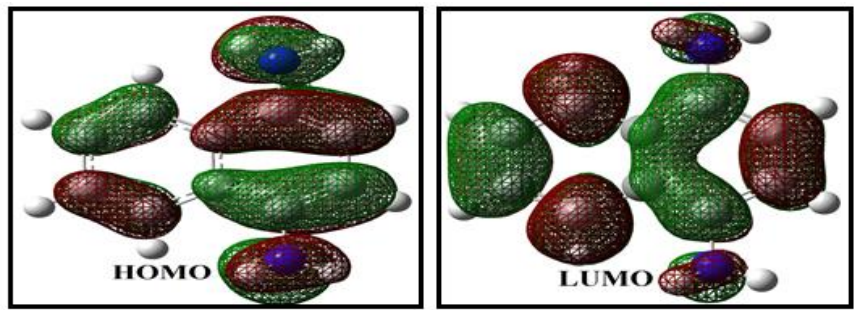

Figure (6): DFT Cal., HOMO and LUMO level of molecule 5
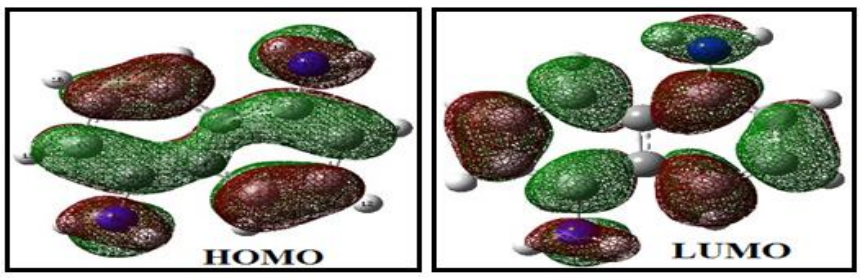

Figure (7): DFT Cal., HOMO and LUMO level of molecule 6 


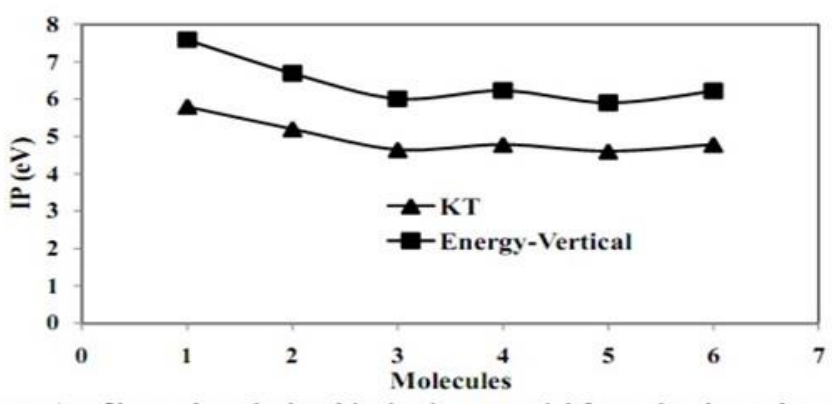

Figure (8): Shows the calculated ionization potential for molecules under study.

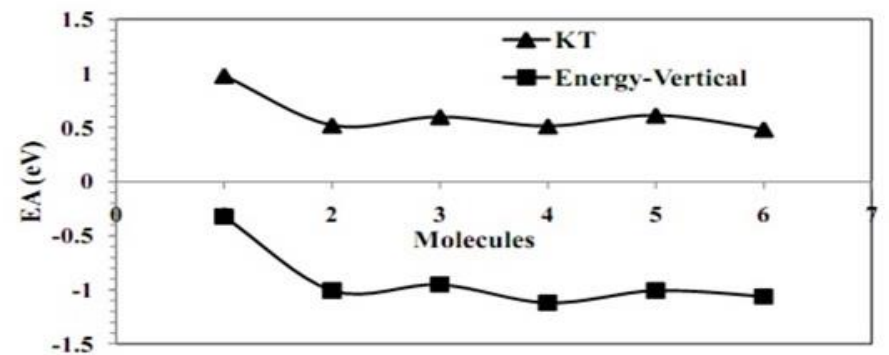

Figure (9) : Shows the calculated electron affinity for molecules under study.

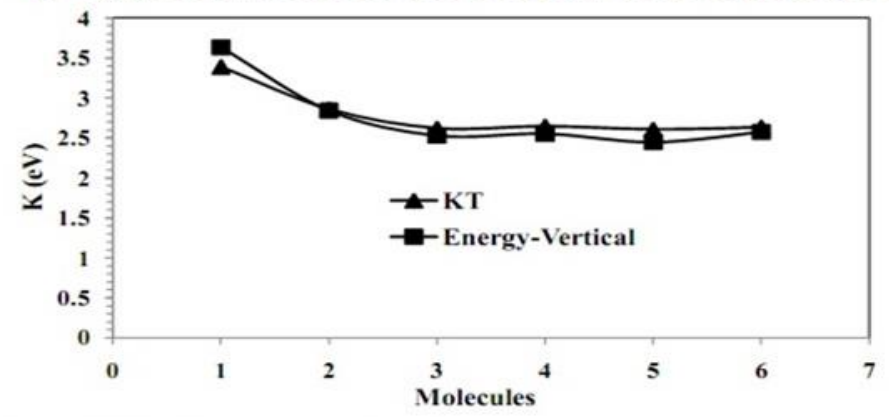

Figure (10) : Shows the calculated chemical potential for molecules under study

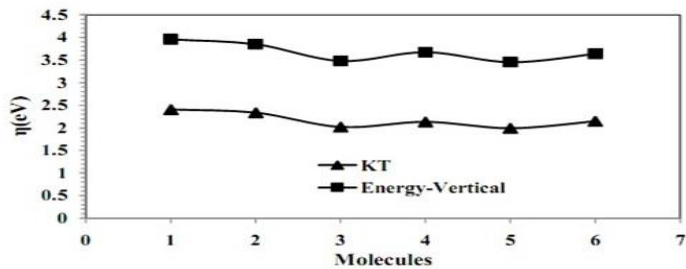

Figure (11): Shows the calculated absolute hardness for molecules under study.

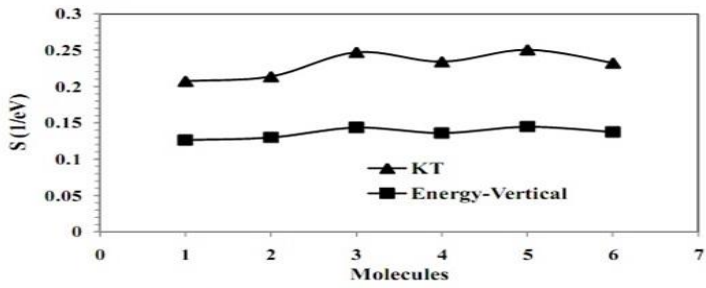

Figure (12) : Shows the calculated absolute softness for molecules under study.

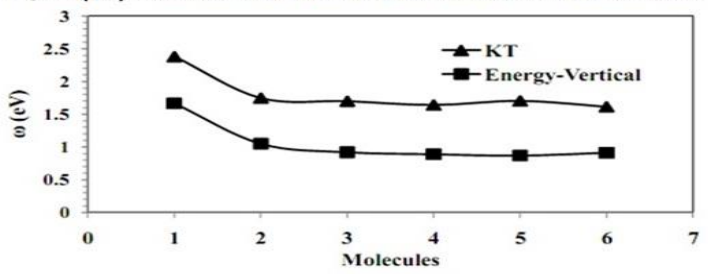

Figure (13) : Shows the calculated electrophilic index for molecules under study.

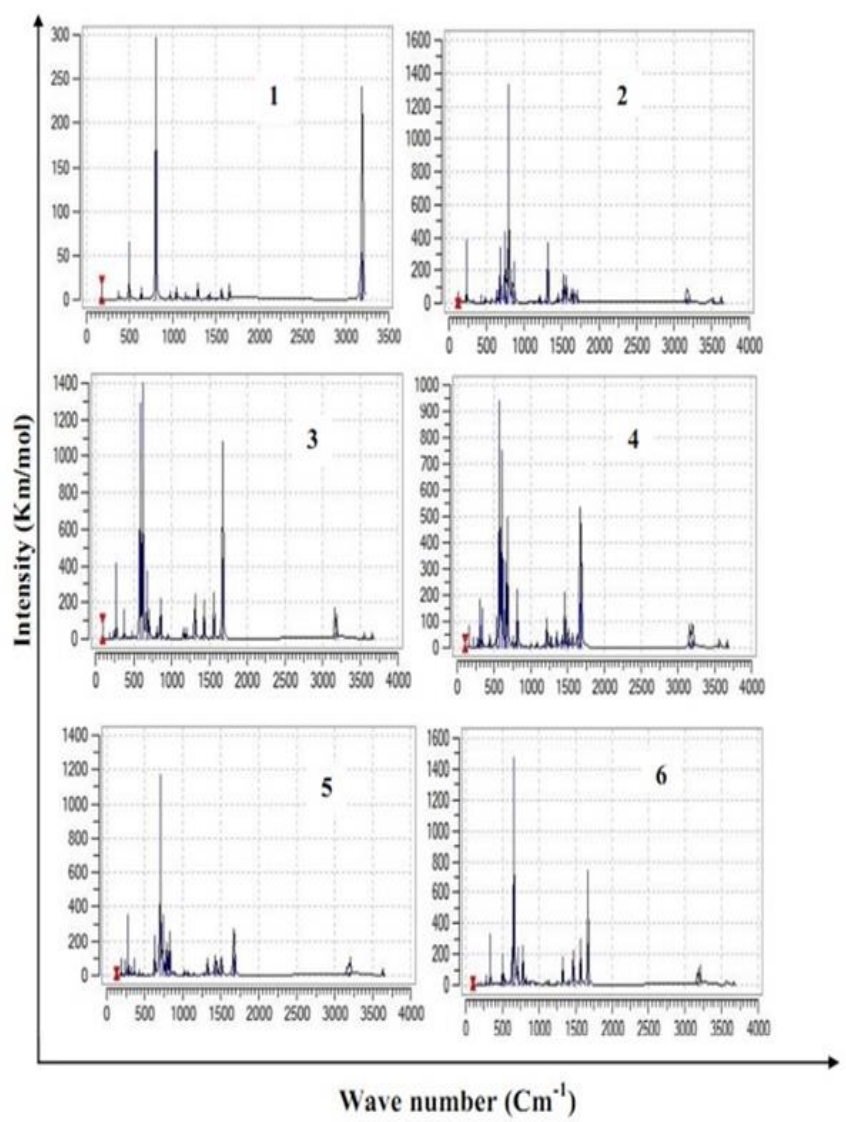

Figure (14) : Shows the calculated IR spectral frequencies for molecules under study.

\section{$\underline{\text { References }}$}

[1] R. Ruiterkamp , N. L .J Cox, M. Spaans, L. Kaper, B. H. Foing, F.Salama and P. Ehrenfreund, Astron. Astrophys 2005.

[2] A. V. Kukhta ,J. Appl. Spectrosc., 70 (2003)165.

[3] H. S. Nalwa (Ed), Handbook of Organic Electronics and Photonics,(Los Angeles, CA: American ScientificPublishers), 2006

[4] A. V. Kukhta, Mol. Cryst. Liq. Cryst, 427 (2005) 71.

[5]A. V. Kukhta, I. N. Kukhta, N. A. Kukhta,O.L.Neyra and E. Meza, J.Phys. B: At. Mol. Opt. Phys., 41 (2008) 205701. 
[6] R. T. Morrison and R.N. Boyd, Organic Chemistry, 6th Edition, New York University, USA, 2005.

[7] C.W. Tang, S.A. Van Slyke, Appl. Phys. Lett., 51 (1987) 913.

[8] B. Zhenan (Ed.), Organic Field-Effect Transistors, CRC Press, Abingdon, 2007.

[9] D. Glossman-Mitnik , D. Barraza-Jiménez , Alberto Flores-Hidalgo,Luz María RodríguezValdez, Journal of Molecular Structure: THEOCHEM, 863 (2008) 99-104.

[10] B.A. Saleh, J. Mol. Struct. THEOCHEM, 915 (2009) 47.

[11] B.A. Saleha, H.A. Aboodb, R. Miyamotoc and M. Bortoluzzi, J. Iran.Chem. Soc., 8 (2011) 653661.

[12] M. J. Frisch, G. W. Trucks, H. B. Schlegel et al., Gaussian 09, Revision A.02,Gaussian, Inc., PA, Wallingford CT. 2009.

[13] C. Lee, W. Yang, R.G. Parr, Phys. Rev. B, 37 (1988) 785.

[14] A.D. Becke, Phys. Rev. A, 38 (1988) 3098.

[15] A.D. Becke, J. Chem. Phys., 98 (1993) 5648.

[16] J. Engelberts, R. Havenith, J. Van Lenthe, L. Jenneskens, P. Fowler, Inorg. Chem., 44(2005) 52266.

[17] J. C. Santos, W. Tiznado, R. Contreras, P. Fuentealba, J. Chem. Phys., 120 (2004) 1670.

[18] J. C. Santos, J. Andres, A. Aizman, P. Fuentealba, J. Chem. Theory Comput, 1 (2005) 83.

[19] P. Udhayakala, T. V. Rajendiran, S. Seshadri, and S. Gunasekaran, J.Chem. Pharm. Res., 3 (2011) 610-625.

[20] S. Gümüs, Turk. J. Chem., 35 (2011) 803-808.

[21] K. Sadasivam, R. Kumaresan, Computational and Theoretical Chemistry, 963 (2011) 227-235.
[22] A. Demetrio Da Silva, V. Coropceanu, D. Fichou et al., Phil. Trans.R. Soc. A, 365 (2007) 14351452 .

[23] M. Oftadeh, S. Naseh, M. Hamadanian, Computational and Theoretical Chemistry, 966 (2011) 20- 25.

[24] N. Ketkar et al., J. Mol. Struc., 77(1981) 127.

[25] P. Ravi, G. M. Gory, S. P. Tewari, and A. K. Sikder, Journal of Energetic Materials, 29 (2011) 209-227.

[26] X. Ming-Hua, SU Ning-Hai, S. WU, Chinese J. Struct. Chem., 27(2008) 421-425.

[27] Z. Wang, S.WU, J.Serb. Chem. Soc. 73 (2008) 1187-1196.

[28] S. Lias, Ionization energy evaluation, in: P. J. Linstrom, W. G. Mallard (Eds.), NIST Chemistry WebBook, NIST Standard Reference Database Number 69, National Institute of Standards and Technology http://webbook.nist.gov, Gaithersburg MD, 2005.

[29] A. Srivastava and V. B. Singh, Indian J. Pure \& Appl. Phys., 45(2007) 714-720.

[30] E. Kavitha, N. Sundaraganesan and S. Sebastian, Indian J. Pure \&Appl. Phys., 48(2010) 20-30. 